\title{
Electrically Conductive Polymer Composite from Polypyrrole and Electrodeposited Poly( $p$-phenylene terephthalamide) Film
}

\author{
Keiko KogA, Takao IIno, Shigeyuki UeTA, \\ and Motowo TAKAYANAGI \\ Faculty of Engineering, Kyushu Sangyo University, \\ Matsukadai 2-3-1, Higashi-ku, Fukuoka 813, Japan
}

(Received October 1!, 1988)

\begin{abstract}
Electrically conductive composites from polypyrrole (PPy) and poly $(p$ phenylene terephthalamide) (PPTA) were formed by electropolymerization of pyrrole on the electrode covered with PPTA film prepared by electrolysis of PPTA polyanions dissolved in dimethylsulfoxide. For the PPTA film annealed above $250^{\circ} \mathrm{C}$, the polymerization of pyrrole hardly took place. Based on DSC measurements, it was found that the remaining solvent of PPTA film was closely related to composite formation. The morphologies of the composites varied, depending on the supporting electrolytes of tetraethylammonium $p$-toluenesulfonate and lithium perchlorate. The conductivity of the composite was $5-50 \mathrm{~S} \mathrm{~cm}^{-1}$. The composite showed improved mechanical properties: tensile strength was $142 \mathrm{MPa}$ and tensile modulus was $6.2 \mathrm{GPa}$ for the $\mathrm{PPy}\left(\mathrm{TsO}^{-}\right)$/ PPTA composite, where $\mathrm{TsO}^{-}$denotes the $p$-toluenesulfonate ion. The temperature dependence of the dynamic viscoelasticity of the $\mathrm{PPy}\left(\mathrm{TsO}^{-}\right) / \mathrm{PPTA}$ composite was well explained by Takayanagi's two-phase model, which was also consistent with SEM observation. The conductivities of the composites doped with $p$-toluenesulfonate and perchlorate were both retained at all times up to $150^{\circ} \mathrm{C}$, whereas that of the pure PPy film decreased to $80 \%$ the original value after annealing at $150^{\circ} \mathrm{C}$, being independent of the dopants. PPTA film was dimensionally stable and heat-resistant, and these properties provided a stable conductive composite film.

KEY WORDS Poly( $p$-phenylene terephthalamide) / Polypyrrole / Conductivity / Mechanical Property / Composite /
\end{abstract}

In the last decade, various electrically conductive polymers have been studied extensively. Among them, a considerable number of works on polyheterocyclic polymers such as polypyrrole, polythiophene, and polyaniline were noticed because of their important advantages. These polymers are relatively stable under ambient conditions and can be conveniently synthesized via electropolymerization. ${ }^{1}$ However, generally, they are not free standing films and have poor mechanical properties, which restrict some practical applications of them. In order to improve these mechanical properties, the preparation of the composite from a conductive polymer and conventional insulating polymer has been proposed. ${ }^{2-4}$ The most successful meth- od to form the composite was found to be electropolymerization of the conductive polymer on the electrode covered with the insulating polymer. As a conducting polymer, polypyrrole (PPy) was mostly used due to its high conductivity and good film forming property. As host polymers, poly(vinyl chloride), ${ }^{2.3}$ poly(vinyl alcohol) ${ }^{4}$ copolymer of vinylidene fluoride and trifluoroethylene, ${ }^{5}$ Nafion, ${ }^{6}$ and others were used. In these cases, the host polymers were required to swell with the solvent used for the polymerization of pyrrole.

We attempted to apply $p$-aramid with excellent mechanical properties and heat-resistance to the host polymer of the conductive composite. In the previous paper, ${ }^{7}$ we reported that a poly( $p$-phenylene terephthalamide) 
(PPTA) film was prepared by electrodeposition. The electrolysis of PPTA polyanions dissolved in dimethylsulfoxide (DMSO) resulted in the formation of PPTA gel containing DMSO on the anode. A uniform PPTA film obtained by washing and drying the gel was strong, stiff and heat resistant. It should be noted that as-electrodeposited PPTA film was in a state of a gel containing an organic solvent. The crystallinity and amount of remaining solvent in the PPTA film could be controlled in the process of the film formation from the as-electrodeposited gel. We prepared a PPy/PPTA composite using the PPTA film thus obtained as a host polymer and polymerizing pyrrole in it electrochemically. In this paper, the preparation conditions of PPy/ PPTA composite, its conductivity, morphology, mechanical properties and thermal stability are reported.

\section{EXPERIMENTAL}

\section{Preparation of the Composite}

Electrodeposition of PPTA was conducted in the same manner as previously reported. ${ }^{7}$ PPTA of $\bar{M}_{v}=50,000$ was supplied by Asahi Chemical Industry Co., Ltd. in powder form. The metalation reaction of PPTA was accomplished by the procedure of Takayanagi and Katayose, ${ }^{8}$ which converted PPTA into the polyanion dissolved in DMSO. $2.5 \mathrm{~g}$ of PPTA was added to $1 \mathrm{~L}$ of DMSO including sodium methylsulfinylcarbanion formed from $\mathrm{NaH}$ and DMSO. The electrolysis of the solution was carried out galvanostatically under the condition of $2.5 \mathrm{mAcm}^{-2}$ for $7 \mathrm{~min}$. Electrodeposited PPTA gel containing DMSO was stripped from the electrode and immersed in acetonitrile. The gel was dried on an ITO glass plate at room temperature for one day to form a PPTA-coated electrode. The thickness of the PPTA film was $16 \mu \mathrm{m}$.

Pyrrole was electrochemically polymerized onto the PPTA-coated electrode in a twoelectrode cell containing $1 \mathrm{M}$ pyrrole and
$0.3 \mathrm{M}$ supporting electrolyte in acetonitrile by applying a constant voltage of $5 \mathrm{~V}$ for $5 \mathrm{~min}$ between the ITO electrode and the stainless steel plate as a counter electrode in nitrogen atmosphere. To examine the suitable condition of the PPTA film as a host polymer of the composite, the PPTA film on the ITOglass was annealed at the temperatures ranging from $150^{\circ} \mathrm{C}$ to $300^{\circ} \mathrm{C}$ for $30 \mathrm{~min}$ before polymerization of pyrrole. Using these electrodes, the current density during the polymerization of pyrrole was measured as a function of time. In this case, lithium perchlorate was used as a supporting electrolyte. Tetraethylammonium $p$-toluenesulfonate was also used in other cases. Pyrrole (Wako Pure Chemical, 99\%), tetraethylammonium $p$-toluenesulfonate (Fluka Chemie AG, 98\%), and $\mathrm{LiClO}_{4}$ (Wako Pure Chemical, 98\%) were used as received. Spectral grade acetonitrile was used without further purification.

After polymerization, the composite film was removed from the electrode, rinsed with acetonitrile and dried at room temperature.

\section{Characterization of the Composites}

Conductivity of the composite was measured using a standard four-probe technique. Thermal measurements were performed by DSC-8230 (Rigaku Denki) at heating rate of $10^{\circ} \mathrm{C} \mathrm{min}{ }^{-1}$ in nitrogen atmosphere. X-ray diffraction measurements were made with a diffractometer (Rigaku Denki, Geiger flex RAD IIIA) in a reflection mode. Mechanical properties were measured by a Tensilon tensile tester and a Rheovibron DDV-III viscoelastometer (Orientec). The density was measured by the floating method in a carbon tetrachlorideethanol mixture. A PPy content in the composite was estimated from the increase of the weight after the polymerization of pyrrole. The morphology of the composite was studied by scanning electron microscope (SEM) (Hitachi $\mathrm{S}-510)$. In order to clarify how the PPy was incorporated in the PPTA texture, the composites were etched by the $\mathrm{NaH}-\mathrm{DMSO}$ re- 
agent to remove PPTA and observed by SEM.

The thermal stability of the composite was estimated by measuring the conductivity at room temperature after annealing at the temperature ranging from $40-230^{\circ} \mathrm{C}$ for $10 \mathrm{~min}$. One sample was successively subjected to annealing and measurement of the conductivity.

\section{RESULTS AND DISCUSSION}

\section{Preparation Conditions of PPy/PPTA Com- posite}

Figure 1 shows the current density during polymerization of pyrrole in the PPTA film. PPTA film annealed below $200^{\circ} \mathrm{C}$ showed the electrolytical current to be associated with polymerization of pyrrole, but the current decreased remarkably as the PPTA film was annealed at higher temperatures than $200^{\circ} \mathrm{C}$. No polymerization of pyrrole took place in the PPTA film annealed above $250^{\circ} \mathrm{C}$. Such a limitation of polymerization depends upon the degree of removal of solvent in PPTA film as proved by the following observations.

Figure 2 shows the DSC curves of the unannealed PPTA film, the PPy/PPTA composite and the PPTA film annealed at $300^{\circ} \mathrm{C}$. Endothermic peaks around $80^{\circ} \mathrm{C}$ and $130^{\circ} \mathrm{C}$ in the curve of the unannealed PPTA film are considered to originate from the desorption of water and DMSO in the film, respectively. In the curve of the PPy/PPTA composite, the peak around $80^{\circ} \mathrm{C}$ lowered and the one around $130^{\circ} \mathrm{C}$ disappeared. In addition, the crystallinity of the PPTA film increased remarkably by annealing above $250^{\circ} \mathrm{C}$ as seen by the increase in density from 1.40 to 1.45 . These findings suggest that PPy grows in the swollen part of PPTA film, excluding the solvent. The disordered region in the PPTA may swell. In addition, from the layer-structure characteristic of the electrodeposited PPTA film, ${ }^{7}$ the regions between the layers are supposed to swell more easily, as supported by the following SEM observation.

By annealing, the orientation of the crystal

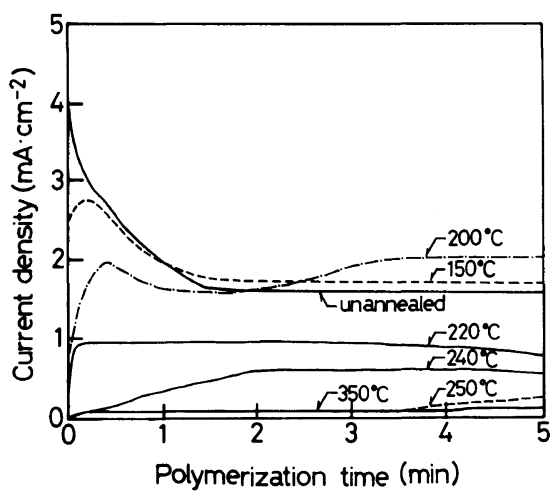

Figure 1. Electrolytic current density in polymerization of pyrrole on a PPTA-coated electrode $v s$. polymerization time. PPTA films were annealed at various temperatures prior to polymerization of pyrrole.

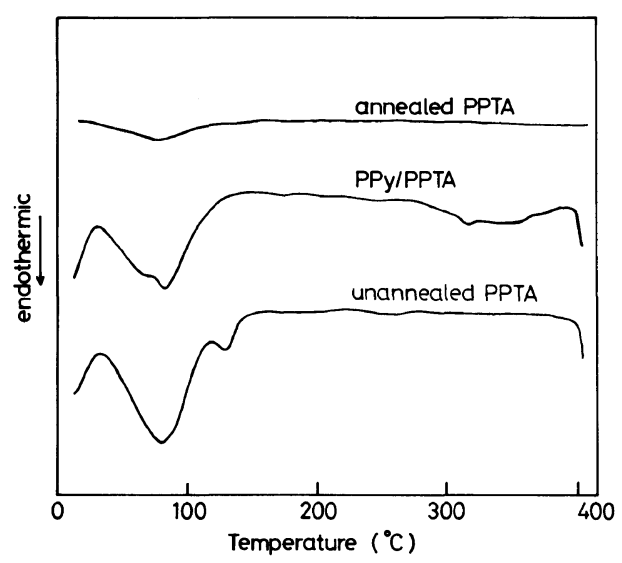

Figure 2. DSC curves of unannealed PPTA film, PPy $\left(\mathrm{TsO}^{-}\right)$/PPTA composite film, and PPTA annealed at $300^{\circ} \mathrm{C}$.

in the PPTA film also changed as previously reported. ${ }^{7}$ Figure 3 shows the diffraction intensity ratio of the (200) reflection to the (110) reflection for the PPTA film annealed at the indicated temperatures for $30 \mathrm{~min}$. The increase of this ratio implied that the hydrogenbonding sheets of the PPTA crystals changed from the perpendicular to the parallel alignment to the film surface. This ratio increased remarkably above $300^{\circ} \mathrm{C}$. The alignment of the hydrogen-bonding sheets of PPTA film might be related to the incorporation of PPy in the PPTA film, when considering that the per- 


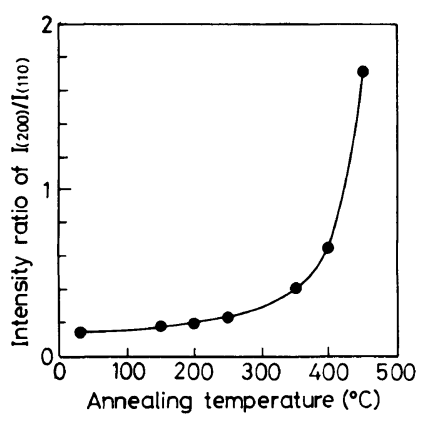

Figure 3. Diffraction intensity ratio of $I_{(200)} / I_{(110)} v s$. annealing temperature for the PPTA film.

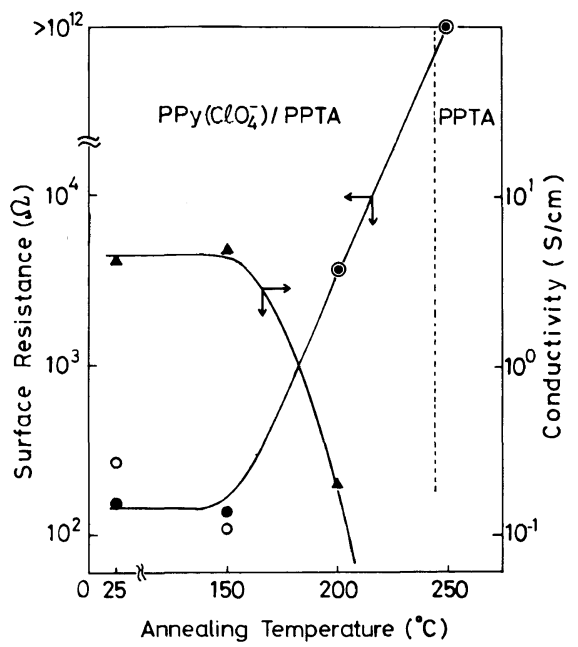

Figure 4. Conductivities and surface resistance of the films prepared under the conditions described Figure 1. Open circles are surface resistances of the solution side and filled circles are those of the electrode side.

pendicular alignment may be more appropriate for the pyrrole and the dopant anion to diffuse in the PPTA film, pushing out the planes bound by the van der Waals force.

Figure 4 shows the conductivity and surface resistance of $\mathrm{PPy}\left(\mathrm{ClO}_{4}^{-}\right)$/PPTA composites prepared under the conditions in Figure 1. Pyrrole was polymerized first on the electrode side of the film and grew in the PPTA film towards the solution side. Using an unannealed PPTA film, the surface resistance of the solution side of the composite was found to be higher than that of the electrode side because PPy did not grow sufficiently on the surface of the solution side. Conductivity of the PPy/ PPTA composite decreased with increasing annealing temperature. This well corresponds to the observation that the amount of PPy formed in proportion to the integrated current density decreased with increasing annealing temperature as seen in Figure 1. The PPy/ PPTA composite was not formed when the PPTA film was annealed above $250^{\circ} \mathrm{C}$. When the PPTA film was obtained by coagulating the electrodeposited PPTA gel with acidic water and drying, the polymerization current of pyrrole was small and the incorporation of PPy in the matrix film took a longer time. This is ascribed to the high crystallinity of the film coagulated with acidic water in comparison with the one coagulated with acctonitrile. The acidic water used here also neutralized $\mathrm{Na}^{+}$ ions incorporated in PPTA film during the electrodeposition. The state of PPTA used for the composite depends on the kind of solvents employed for exchanging the DMSO molecules contained in the as-electrodeposited PPTA gel.

It is concluded that the existence of the disordered region in the PPTA film is necessary to form a composite by electropolymerization of pyrrole in the film, providing the swollen part in which pyrrole monomers and supporting electrolyte are able to diffuse.

\section{Morphology}

The morphologies of the composite films were different, depending on the dopant anion species. Figure 5 shows the SEM photographs of the PPy $\left(\mathrm{TsO}^{-}\right)$/PPTA composite: (a) the fractured surface, (b) the surface appearance in the solution side, (c) the surface appearance in the electrode side, (d) the PPy component in the solution side remained after etching, (e) the appearance of PPy inside the film, as revealed by etching, and (f) the surface appearance in electrode side after etching. Many small projections of PPy were observed on the surface corresponding to the solution side at the polymerization of pyrrole. PPy particles $50 \mu \mathrm{m}$ 


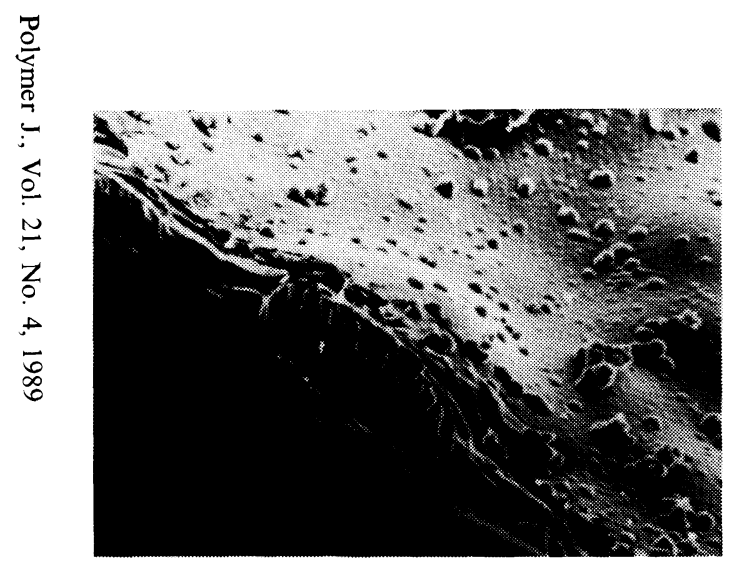

(a) fractured surface

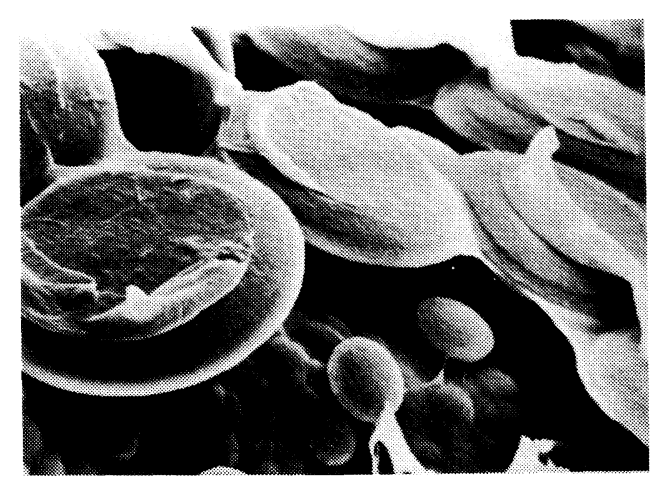

(d) solution side (etched)

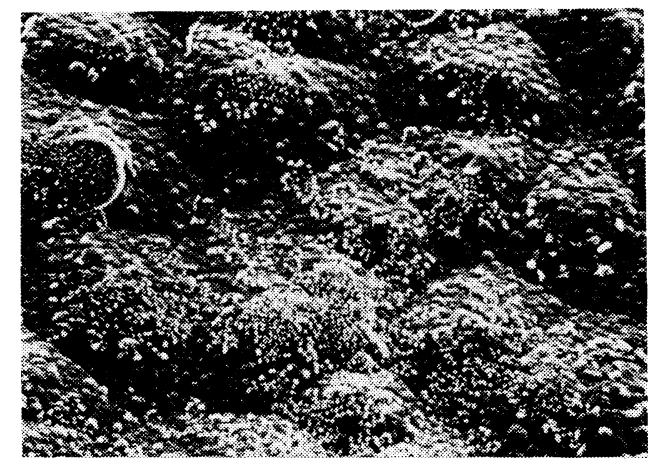

(b) solution side

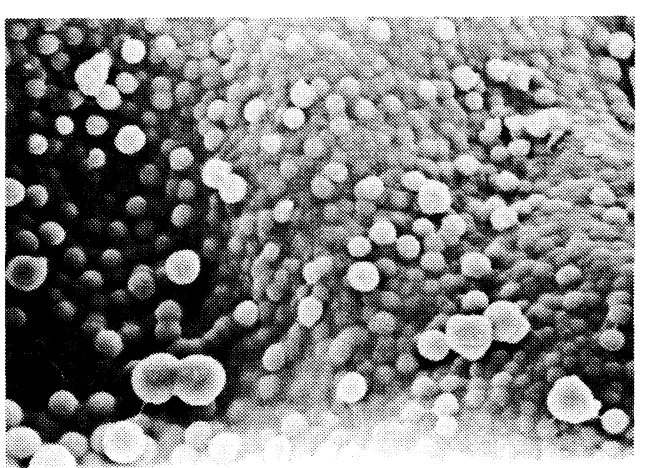

(e) inside (etched)

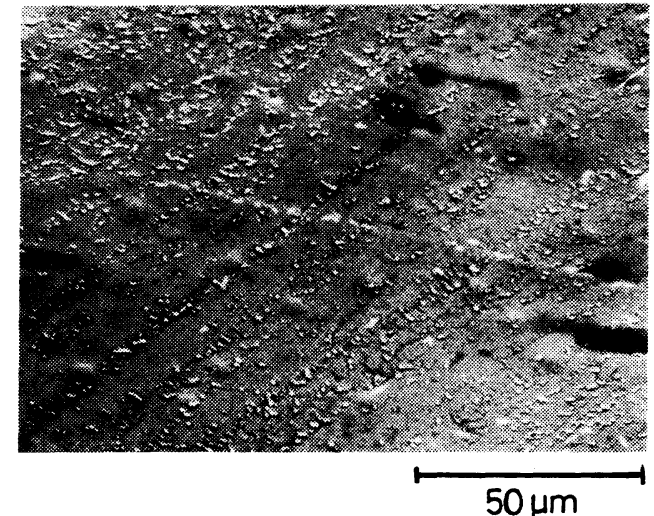

(c) electrode side

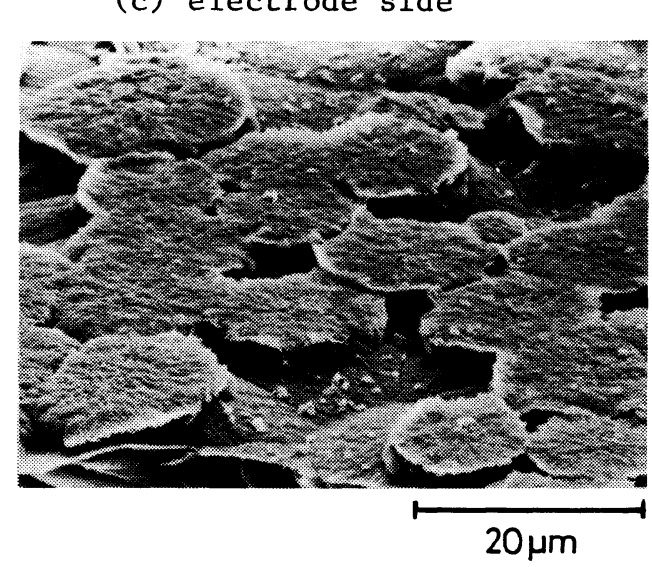

(f) electrode side (etched)

Figure 5. SEM photographs of $\mathrm{PPy}\left(\mathrm{TsO}^{-}\right)$/PPTA composites. (d)-(f) are for the sample etched by the reagent of NaH and DMSO. 


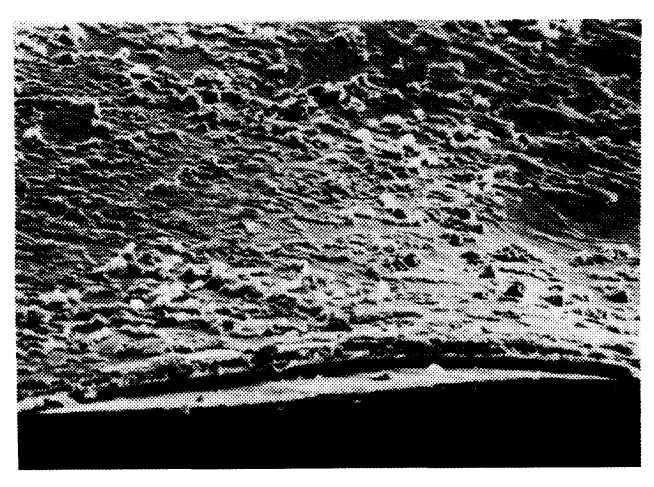

(a) solution side

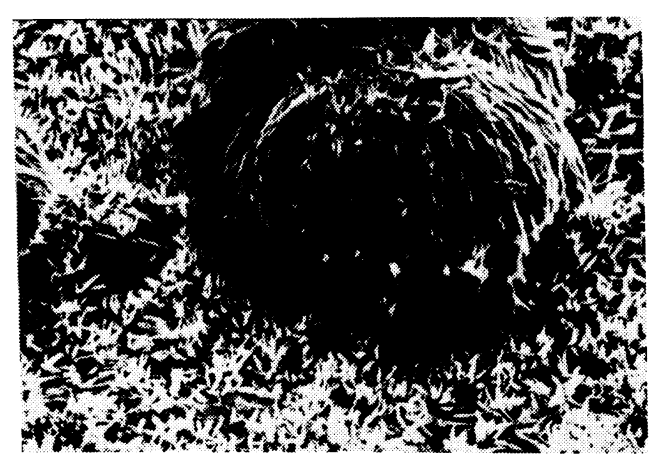

(c) solution side (etched)

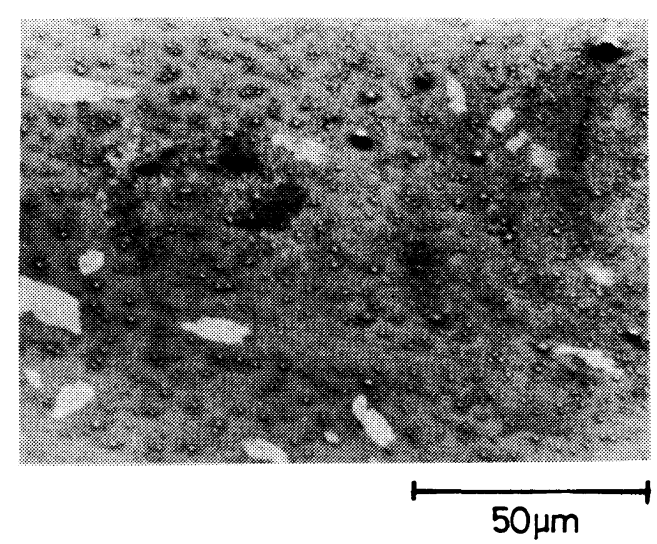

(b) electrode side

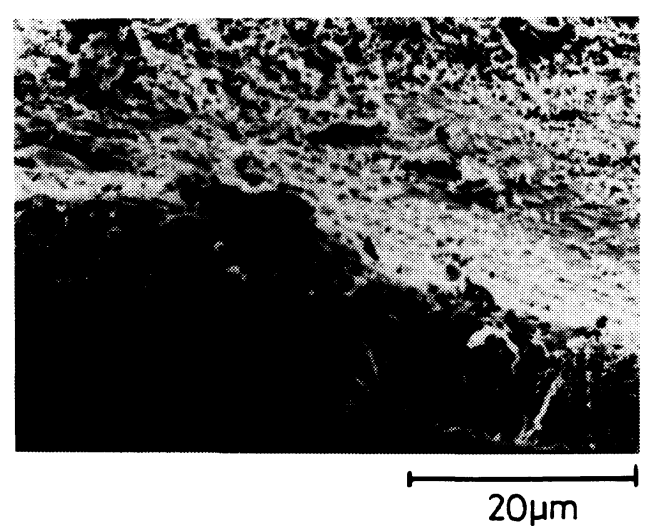

(d) fractured surface (etched)

Figure 6. SEM photographs of $\mathrm{PPy}\left(\mathrm{ClO}_{4}{ }^{-}\right)$/PPTA composites. (c) and (d) are for the sample etched by the reagent of $\mathrm{NaH}$ and DMSO.

in diameter grew near the surface in the solution side by pushing up the layers of PPTA, which appeared like a hill on the surface, in contrast to the flat surface of the electrode side. Use of $p$-toluenesulfonate as a dopant gave the pancake-like particles of PPy inside the composite film, especially the PPy particles located close to the surface layer increased in size, as seen in Figures 5(d) and (e).

Figure 6 shows SEM photographs of the PPy $\left(\mathrm{ClO}_{4}{ }^{-}\right)$/PPTA: (a) the fractured surface, (b) the surface appearance in the electrode side, (c) the PPy component in the solution side remained after etching, and (d) the frac-

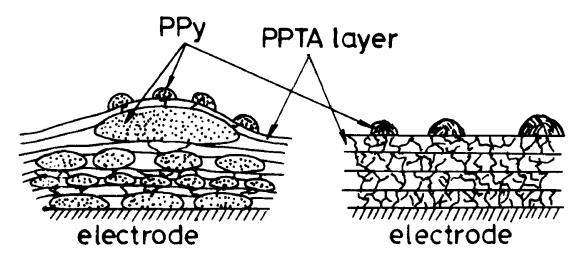

Figure 7. Schematic representation of the structure of (a) PPy $\left(\mathrm{TsO}^{-}\right) / \mathrm{PPTA}$ and (b) PPy $\left(\mathrm{ClO}_{4}{ }^{-}\right) / \mathrm{PPTA}^{-}$

tured surface as revealed by, etching. Use of perchlorate as a dopant gave fibrillar networks of PPy in a PPTA film.

From these observations, the morphologies of $\mathrm{PPy}\left(\mathrm{TsO}^{-}\right) / \mathrm{PPTA}$ and $\mathrm{PPy}\left(\mathrm{ClO}^{-}\right) / \mathrm{PPTA}$ are schematically represented by Figures 
7(a) and (b), respectively. The manner of the incorporation of PPy into the matrix film depends on the morphology of the matrix film as well as the dopant anion species. As mentioned above, electrodeosited PPTA film takes the layer-structure. Although the SEM observation does not give detailed information on the fine structure of the PPTA film, PPTA probably forms the domains composed of extended chains lying parallel to the film surface in each layer because of its rigidity. Possibly, it is difficult for the bulky $p$-toluenesulfonate anions to diffuse in each of the PPTA layers, so that $\mathrm{PPy}\left(\mathrm{TsO}^{-}\right)$grows mainly between the neighboring PPTA layers, resulting in the pancake-like particles. The morphology of PPy found here differs from the network structure of $\mathrm{PPy}\left(\mathrm{TsO}^{-}\right)$in the copolymer of vinylidene fluoride and trifluoroethylene reported by Niwa et al. ${ }^{5}$ High crystallinity is common to these two matrix polymers, but they crystallize to different morphologies. While the copolymer of flexible polymer crystallizes in foled-chain-crystal, the PPTA of rigid-rod polymer takes the layer-structure as mentioned above. Thus, the morphology of PPy varies depending on the matrix film morphology. On the other hand, the perchlorate anions with more compact shape diffuse more easily in the layer of PPTA, and PPY $\left(\mathrm{ClO}_{4}{ }^{-}\right)$grows in a mat of PPTA layers to form a more uniform network structure.

\section{Mechanical Properties}

Figure 8 shows the results of tensile testing of PPy/PPTA composites together with those of pure PPTA and PPy for comparison. The stress-strain curve of $\mathrm{PPy}\left(\mathrm{TsO}^{-}\right) / \mathrm{PPTA}$ was located between the curve of PPTA film annealed at $200^{\circ} \mathrm{C}$ and that of pure PPy. Unannealed PPTA film as a host polymer had a fairly large elongation-to-break because of the plasticization effect by the remaining solvent and was softer than the pure PPy. This is consistent with the hypothesis that the polymerization of pyrrole proceeds in the swollen part of PPTA film, excluding the solvent molecules.

Table I shows the conductivity and mechanical properties of the PPy/PPTA composites and pure PPy films using $p$-toluenesulfo-

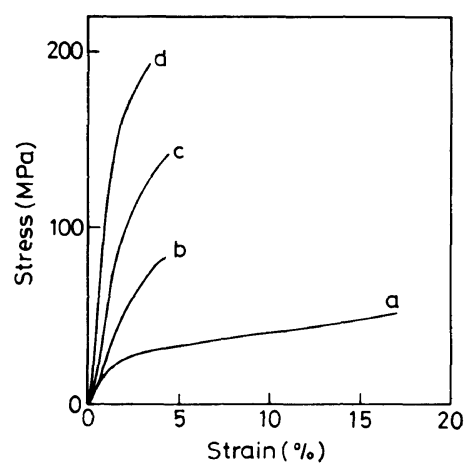

Figure 8. Stress-strain curves of (a) unannealed PPTA film, (b) pure $\mathrm{PPy}\left(\mathrm{TsO}^{-}\right)$film, (c) $\mathrm{PPy}\left(\mathrm{TsO}^{-}\right) / \mathrm{PPTA}^{-}$ composite, and (d) PPTA film annealed at $200^{\circ} \mathrm{C}$.

Table I. Conductivities and mechanical properties of PPy and PPy/PPTA composite

\begin{tabular}{|c|c|c|c|c|c|}
\hline \multirow{2}{*}{ Sample } & Conductivity & Tensile strength & Tensile modulus & Elongation at break & Content of PPy \\
\hline & $\mathrm{S} \mathrm{cm}^{-1}$ & $\mathrm{MPa}$ & $\mathrm{GPa}$ & $\%$ & $w t \%$ \\
\hline $\mathrm{PPy}\left(\mathrm{TsO}^{-}\right)$ & 80 & 54 & 2.5 & 7.5 & - \\
\hline $\mathrm{PPy}\left(\mathrm{TsO}^{-}\right) / \mathrm{PPTA}$ & 20 & 142 & 6.2 & 4.4 & 36 \\
\hline $\mathrm{PPy}\left(\mathrm{TsO}^{-}\right) / \mathrm{PPTA}$ & 57 & 61 & $1.7^{\mathrm{b}}$ & 1.2 & 59 \\
\hline $\mathrm{PPy}\left(\mathrm{ClO}_{4}^{-}\right)$ & $3^{\mathrm{a}}$ & -- & - & - & 一 \\
\hline $\mathrm{PPy}\left(\mathrm{ClO}_{4}{ }^{-}\right) / \mathrm{PPTA}$ & 5 & 98 & 3.8 & 3.9 & 30 \\
\hline
\end{tabular}

a Rough surface.

b The low modulus was due to void formation. Thickness of the film unusually increased by 3 times as much after composite formation. 
nate and perchlorate anions as dopants. The conductivity and mechanical properties of $\operatorname{PPy}\left(\mathrm{TsO}^{-}\right) / \mathrm{PPTA}$ were superior to those of $\mathrm{PPy}\left(\mathrm{ClO}_{4}^{-}\right) /$PPTA. Although pure PPy$\left(\mathrm{TsO}^{-}\right)$formed a self-supporting film by itself and had fairly good mechanical properties compared to other poly(pyrrolylium anion) films, ${ }^{9}$ the $\mathrm{PPy}\left(\mathrm{TsO}^{-}\right) / \mathrm{PPTA}$ composite had greater strength and modulus. On the other hand, $\mathrm{PPy}\left(\mathrm{ClO}_{4}{ }^{-}\right)$had a poor filmforming property and showed dendritic morphology, but by its forming a composite with PPTA a strong self-supporting film was obtained. The contents of poly(pyrrolylium anion) in the composites were $36 \mathrm{wt} \%$ for $\mathrm{PPy}\left(\mathrm{TsO}^{-}\right) / \mathrm{PPTA}$ of $20 \mathrm{~S} \mathrm{~cm}^{-1}$ and $30 \mathrm{wt} \%$ for $\mathrm{PPy}\left(\mathrm{ClO}_{4}{ }^{-}\right) / \mathrm{PPTA}$ of $5 \mathrm{~S} \mathrm{~cm}^{-1}$.

Figure 9 shows the temperature dependence of the storage modulus $E^{\prime}$ and loss tangent $\tan \delta$ measured at $110 \mathrm{~Hz}$ for the $\mathrm{PPy}\left(\mathrm{TsO}^{-}\right) /$ PPTA film $21 \mu \mathrm{m}$ thick, the PPTA film $16 \mu \mathrm{m}$ thick annealed at $80^{\circ} \mathrm{C}$ for $30 \mathrm{~min}$ and the pure $\operatorname{PPy}\left(\mathrm{TsO}^{-}\right)$film $23 \mu \mathrm{m}$ thick. The moduli of PPTA and $\mathrm{PPy}\left(\mathrm{TsO}^{-}\right)$did not decrease to $250^{\circ} \mathrm{C}$. Small broad peaks at about $50^{\circ} \mathrm{C}$ and $110^{\circ} \mathrm{C}$ were observed on the $\tan \delta$ curve of the PPTA film. The peak at the lower temperature side is assigned to the $\beta$ relaxation, corresponding to the local motion of molecules in its noncrystalline part and the one at the higher temperature side is assumed to be associated with the remaining solvent. As reported in our previous paper, ${ }^{7}$ the $\beta^{*}$ relaxation at $220^{\circ} \mathrm{C}$ was observed for the PPTA film obtained from the gel treated with aqueous hydrochloric acid. The $\beta^{*}$ relaxation of the PPTA film used here seems to be concealed in the background due to the coexisting solvent. There are two peaks at $100^{\circ} \mathrm{C}$ and $150^{\circ} \mathrm{C}$ on the $\tan \delta$ curve of $\mathrm{PPy}\left(\mathrm{TsO}^{-}\right)$. The peak at $100^{\circ} \mathrm{C}$ seems to be associated with the absorbed solvent. The peak at $150^{\circ} \mathrm{C}$ probably corresponds to the local mode of polypyrrole backbone, which is also suggested by the fact that the specific heat varies at about $150^{\circ} \mathrm{C}$ in the DSC curve. This temperature is close to the main peak tem-

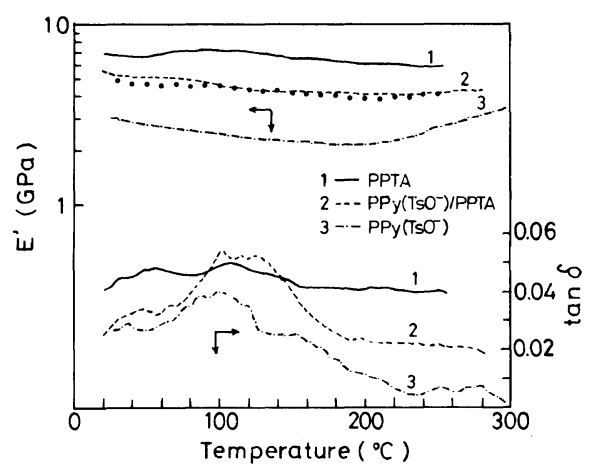

Figure 9. The temperature dependence of $E^{\prime}$ and $\tan \delta$ measured at $110 \mathrm{~Hz}$ for $\mathrm{PPy}\left(\mathrm{TsO}^{-}\right), \mathrm{PPTA}$, and $\mathrm{PPy}\left(\mathrm{TsO}^{-}\right) / \mathrm{PPTA}$. Filled circles represent the values of $E^{\prime}$ of the $\mathrm{PPy}\left(\mathrm{TsO}^{-}\right)$/PPTA composite calculated using Takayanagi's model.

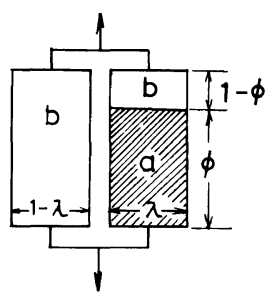

Figure 10. Takayanagi's two-phase model.

perature in the $\tan \delta$ curve for $m$-nitrobenzenesulfonate-doped PPy as reported by Satoh et al. ${ }^{10}$

The modulus of the PPy/PPTA composite was calculated by the following equation, applying Takayanagi's model ${ }^{11}$ assuming the composite to be composed of a two-phase structure of PPy and PPTA.

$$
E^{*}=\lambda\left(\frac{\phi}{E_{\mathrm{a}}{ }^{*}}+\frac{1-\phi}{E_{\mathrm{b}}{ }^{*}}\right)^{-1}+(1-\lambda) E_{\mathrm{b}}{ }^{*}
$$

where $E_{\mathrm{a}}{ }^{*}$ and $E_{\mathrm{b}}{ }^{*}$ represent the complex moduli of PPy and PPTA, respectively, $\lambda$ and $\phi$ are the parameters as shown in Figure 10 and $\lambda \phi$ is equal to the volume fraction of PPy. The values of $\lambda$ and $\phi$ used for calculation were $\lambda=0.488$ and $\phi=0.758$. These values were determined by fitting the calculated value to the observed value of $E^{\prime}$ at $120^{\circ} \mathrm{C}$ under the condition of $\lambda \phi=0.37$. The calculated values of $E^{\prime}$ are plotted in Figure 9. In the 
calculation, the contribution of loss modulus $E^{\prime \prime}$ was ignored because the values of $\tan \delta$ are small. Close agreement between the observed and calculated values indicates that the composite is a two-phase structure in which no specific intermolecular interaction exists between PPy and PPTA. This agrees with the consideration of the morphology as described in the previous section.

\section{Thermal Stability}

Figure 11 shows the relative thermal stability of conductivities for $\mathrm{PPy}\left(\mathrm{TsO}^{-}\right) / \mathrm{PPTA}$ composite and pure $\mathrm{PPy}\left(\mathrm{TsO}^{-}\right)$. The conductivity of the composite remained unchanged still at $150^{\circ} \mathrm{C}$, whereas that of pure PPy film began to decrease from room temperature, becoming $80 \%$ at $150^{\circ} \mathrm{C}$. The thermal stability of the PPy $\left(\mathrm{ClO}_{4}{ }^{-}\right) /$PPTA composite was improved similarly to the $\mathrm{PPy}\left(\mathrm{TsO}^{-}\right) / \mathrm{PPTA}$ till $150^{\circ} \mathrm{C}$. The conductivities of both the composites and doped PPy decreased rapidly above $150^{\circ} \mathrm{C}$. Such a retention of conductivity can be explained by the notion that the rigid molecular frame of PPTA impedes the contraction of the intermolecular distance of PPy caused by removal of the dopants at higher temperature. This explanation does not contradict the absence of specific intermolecular interaction between PPTA and PPy.

In the X-ray diffraction patterns of the PPy/ PPTA composites of both $p$-toluenesulfonatedoped and perchlorate-doped, there appeared several sharp peaks arising from the compounds formed between the remaining $\mathrm{Na}^{+}$cation in the PPTA film and the dopant anion, which disappeared after the composite was rinsed with aqueous hydrochloric acid. Some peaks of the salts increased their intensity by annealing above $150^{\circ} \mathrm{C}$. This suggests that the release of dopant anions from PPy takes place above $150^{\circ} \mathrm{C}$, resulting in the reduction of the conductivity of PPy. More detailed discussion on the effect of dopants on the supramolecular structure will be given in the following paper.

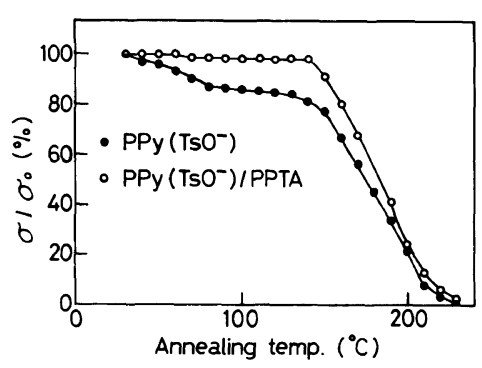

Figure 11. Thermal stability of conductivity for PPy $\left(\mathrm{TsO}^{-}\right) /$PPTA and PPy. $\sigma / \sigma_{0}$ denotes the ratio of conductivity after annealing to the one before annealing.

\section{CONCLUSIONS}

An electroconductive composite of polypyrrole (PPy) and poly ( $p$-phenylene terephthalamide) (PPTA) was formed through electropolymerization of pyrrole in the matrix film of PPTA.

The PPTA film was obtained from the gel formed by electrodeposition of PPTA polyanions dissolved in dimethylsulfoxide. Formation of the composite depends on the state of PPTA which varied by the treatment incurred in the process of going from the gel to the film, e.g., washing, drying and annealing.

The existence of the disordered region in the PPTA film is necessary to form a composite with PPy, providing the swollen part in which pyrrole monomers and supporting electrolyte are able to diffuse.

The morphologies of PPy/PPTA composites are different, depending on the dopant anion species. Use of $p$-toluenesulfonate as a dopant gives pancake-like particles of PPy inside the composite film, which reflects the layer-structure of the matrix film. On the other hand, use of perchlorate gives a fibrillar network of PPy grown in a PPTA film.

PPTA and PPy coexist as two separate phases in the composite and no specific molecular interaction works between them, as was confirmed from SEM observation and analysis of dynamic viscoelasticity.

The PPy/PPTA composite had a conductivi- 
ty of $5-50 \mathrm{~S} \mathrm{~cm}^{-1}$. The modulus of $6.2 \mathrm{GPa}$ and strength of $140 \mathrm{MPa}$ were obtained for the composite with a conductivity of $20 \mathrm{~S} \mathrm{~cm}^{-1}$. The conductivity of the composite was stable as high as $150^{\circ} \mathrm{C}$. Thus, a dimensionally stable, heat-resistant and electroconductive composite film was made with the PPy/PPTA composite.

Acknowledgment. This work was partly supported by a Grant-in-Aid from the Ministry of Education, Science, and Culture of Japan.

\section{REFERENCES}

1. A. F. Diaz and K. K. Kanazawa, J. Chem. Soc., Chem. Commun., 635 (1979).
2. O. Niwa, M. Hikita, and T. Tamamura, Makromol. Chem., Rapid Commun., 6, 375 (1985).

3. M-A. DePaoli, R. J. Waltman, A. F. Diaz, and J. Bargon, J. Polym. Sci., Polym. Chem. Ed., 23, 1687 (1985).

4. S. E. Linsey and G. B. Street, Synth. Met., 10, 67 $(1984 / 85)$.

5. O. Niwa, M. Kakuchi, and T. Tamamura, Macromolecules, 20, 749 (1987).

6. R. Qian and J. Qiu, Polym. J., 19, 157 (1987).

7. K. Koga, S. Ueta, and M. Takayanagi, Polym. J., 20, 639 (1988)

8. M. Takayanagi and T. Katayose, J. Polym. Sci., Polym. Chem. Ed., 19, 1133 (1981).

9. L. J. Buckley, D. K. Royland, and G. E. Wnek, J. Polym. Sci., Polym. Phys. Ed., 25, 2179 (1987).

10. M. Satoh, H. Yamasaki, and S. Aoki, Synth. Met., 20, 79 (1987).

11. M. Takayanagi, H. Harima, and Y. Iwata, Mem. Fac. Eng. Kyushu Univ., 23, 1 (1963). 